\title{
Accuracy and precision of oscillometric blood pressure in standing conscious horses
}

Olsen, Emil; Pedersen, Tilde Louise Skovgaard; Robinson, Rebecca; Andersen, Pia Haubro

Published in:

Journal of Veterinary Emergency and Critical Care (Online Edition)

DOI:

$10.1111 /$ vec. 12411

Publication date:

2016

Document version

Publisher's PDF, also known as Version of record

Citation for published version (APA):

Olsen, E., Pedersen, T. L. S., Robinson, R., \& Andersen, P. H. (2016). Accuracy and precision of oscillometric blood pressure in standing conscious horses. Journal of Veterinary Emergency and Critical Care (Online Edition), 26(1), 85-92. https://doi.org/10.1111/vec.12411 


\title{
Accuracy and precision of oscillometric blood pressure in standing conscious horses
}

\author{
Emil Olsen, DVM, PhD; Tilde Louise Skovgaard Pedersen, DVM; Rebecca Robinson, BVSc, \\ MVetMed, DECVAA and Pia Haubro Andersen, DVM, PhD, DVSci
}

\begin{abstract}
Background - Arterial blood pressure (BP) is a relevant clinical parameter that can be measured in standing conscious horses to assess tissue perfusion or pain. However, there are no validated oscillometric noninvasive blood pressure (NIBP) devices for use in horses.

Animals - Seven healthy horses from a teaching and research herd.

Hypothesis/Objective - To evaluate the accuracy and precision of systolic arterial pressure (SAP), diastolic arterial pressure (DAP), and mean arterial pressure (MAP) in conscious horses obtained with an oscillometric NIBP device when compared to invasively measured arterial BP.

Methods - An arterial catheter was placed in the facial or transverse facial artery and connected to a pressure transducer. A cuff for NIBP was placed around the tail base. The BP was recorded during normotension, dobutamine-induced hypertension, and subnormal BP induced by acepromazine administration. Agreement analysis with replicate measures was utilized to calculate bias (accuracy) and standard deviation (SD) of bias (precision).

Results - A total of 252 pairs of invasive arterial BP and NIBP measurements were analyzed. Compared to the direct BP measures, the NIBP MAP had an accuracy of $-4 \mathrm{~mm} \mathrm{Hg}$ and precision of $10 \mathrm{~mm} \mathrm{Hg}$. SAP had an accuracy of $-8 \mathrm{~mm} \mathrm{Hg}$ and a precision of $17 \mathrm{~mm} \mathrm{Hg}$ and DAP had an accuracy of $-7 \mathrm{~mm} \mathrm{Hg}$ and a precision of $14 \mathrm{~mm} \mathrm{Hg}$.

Conclusions and Clinical Relevance - MAP from the evaluated NIBP monitor is accurate and precise in the adult horse across a range of $\mathrm{BP}$, with higher variability during subnormal BP. MAP but not SAP or DAP can be used for clinical decision making in the conscious horse.
\end{abstract}

(J Vet Emerg Crit Care 2016; 26(1): 85-92) doi: 10.1111/vec.12411

Keywords: arterial blood pressure, acepromazine, dobutamine, equinen, oninvasive blood pressure

\section{Abbreviations}

BP blood pressure

DAP diastolic arterial pressure

IBP invasive arterial blood pressure

MAP mean arterial pressure

NIBP noninvasive blood pressure

SAP systolic arterial pressure

From the Department of Large Animal Sciences, Faculty of Health and Medical sciences, University of Copenhagen (Olsen, Pedersen), the Department of Clinical Science and Services, The Royal Veterinary College, University of London (Robinson), and the Department of Clinical Sciences, Swedish University of Agricultural Sciences (Andersen).

This work was supported by a grant from the Danish equine insurance company "Kongeriget Danmark," KDH.

Presented in part at the ACVIM Forum, June 2011, in Denver CO and as a public presentation for the master thesis defense of the second author.

Address correspondence and reprint requests to

Dr. Emil Olsen, Department of Large Animal Sciences, Faculty of Health and Medical Sciences, University of Copenhagen, Hojbakkegaard Allé 5, 2630 Taastrup, Denmark. Email: eo@sund.ku.dk

Submitted July 02, 2013; Accepted March 20, 2014.
SVR systemic vascular resistance

\section{Introduction}

Blood pressure (BP) measurement in critically ill, conscious, standing horses is useful for assessment of dynamic cardiovascular changes related to systemic inflammatory response syndrome (SIRS), septicemia, cardiac failure, ${ }^{1}$ endotoxemia, ${ }^{2}$ hypovolemia, ${ }^{1,3,4}$ pain, ${ }^{5}$ and equine metabolic syndrome. ${ }^{6,7}$ The current reference standard for arterial blood pressure in horses is direct measurement of systolic arterial pressure (SAP) and diastolic arterial pressure (DAP). ${ }^{8}$ Mean arterial blood pressure (MAP) is calculated from these values as a real-time estimate of average BP. Although measurement of MAP is the most clinically applicable and readily available technique to assess a patient's cardiovascular status, arterial BP does not equal arterial blood flow. Mean arterial BP can be calculated by the equation: 


$$
\begin{array}{r}
\operatorname{MAP}(\mathrm{mmHg})=\text { Cardiac Output }(\mathrm{L} / \mathrm{min}) \\
\times \text { Systemic Vascular Resistance }\left(\mathrm{dyn} / \mathrm{s} / \mathrm{cm}^{5}\right) \times 80 .
\end{array}
$$

Therefore, MAP is affected by the relationship between cardiac output and systemic vascular resistance (SVR). If SVR is increased, MAP may be normal or high, but cardiac output, and therefore blood flow, may be compromised. ${ }^{9}$

Direct or invasive arterial blood pressure (IBP) is rarely measured in the standing horse with clinical disease, despite a negative association between preoperative hypotension and survival in horses with colic. ${ }^{10}$ Difficulty in placing and maintaining an arterial catheter in the conscious horse prevents routine use of IBP as a monitoring aid. In addition, direct arterial cannulation of the critically ill patient poses a risk for iatrogenic thrombosis and sepsis ${ }^{11}$ and requires more training, compared to the easy, safe, and noninvasive application of a noninvasive blood pressure (NIBP) cuff. The use of an oscillometric NIBP monitor has been investigated in anesthetized and conscious foals, ${ }^{12,13}$ in anesthetized horses, ${ }^{14-16}$ and standing adult horses. ${ }^{16}$ Oscillometry is routinely used in human medicine and small animal veterinary practice but is less commonly used in large animal practice.

Oscillometric BP measurement devices provide objective and automated measurement of MAP, and then calculate the values for SAP and DAP. These devices may have a diagnostic advantage over other indirect methods (eg, Korotkoff sound detection, Doppler ultrasonic flow detection). ${ }^{1,3}$ MAP is generally considered to best reflect systemic BP, and MAP is generally used for intraoperative clinical decision making. ${ }^{1,17}$

To the authors' knowledge, there are no studies investigating the accuracy and precision of oscillometric NIBP in conscious standing horses during clinically relevant hypo- or hypertension. This evaluation is a necessity for the practical application of any device and cannot be transferred across species. ${ }^{18}$ The objective of this study was to evaluate the accuracy and precision of oscillometric NIBP during periods of normotension, subnormal $\mathrm{BP}$, and hypertension in healthy conscious standing horses, compared to IBP.

\section{Materials and Methods}

Seven trotter mares between 4 and 14 years old (mean age of $9.2 \mathrm{y} \pm$ standard deviation [SD] of $3.2 \mathrm{y}$ ) weighing between 447 and $612 \mathrm{~kg}$ (mean weight of $538 \pm$ $56 \mathrm{~kg}$ ) were included in this study. Horses belonged to the teaching and research herd at the Department of Large Animal Sciences, University of Copenhagen, and were not pregnant or receiving any medications during the data collection period and were judged to be clinically healthy. Horses were excluded from the study if they were obese or if they demonstrated clinical signs of infection or overt pain. Routine physical examination was performed prior to the initiation of the study (on days -7 and -1 ), twice daily during the study, and again the day after conclusion of experimental procedures. All experimental procedures were approved by the Institutional Ethics Committee and the Danish Animal Experimentation Board. The study complied with the Danish Animal Testing Act and the NIH Guide for the Care and Use of Laboratory Animals as well as the Animal (Scientific Procedures) Act of 1986.

\section{Invasive arterial blood pressure}

The skin over the facial and transverse facial arteries was clipped and desensitized with a topical cream $^{\mathrm{a}}$ containing lidocaine and prilocaine. Approximately 60 minutes later, the skin over the artery was aseptically prepared and the artery was cannulated ${ }^{3}$ with a $20 \mathrm{G}$, $45 \mathrm{~mm}$ catheter $^{\mathrm{b}}$ and fixed in place with glue and adhesive polster plast. ${ }^{c}$ Three horses could not be catheterized while standing and were anesthetized to reduce unnecessary pain and distress from the procedure. These horses were premedicated with xylazine ${ }^{\mathrm{d}}$ $(1.0 \mathrm{mg} / \mathrm{kg} \mathrm{IV})$ and atropine ${ }^{\mathrm{e}}(0.005 \mathrm{mg} / \mathrm{kg} \mathrm{IV})$. Anesthesia was induced using ketamine ${ }^{\mathrm{f}}(2.2 \mathrm{mg} / \mathrm{kg} \mathrm{IV}){ }^{19}$ One horse was excluded from the study at this point, as arterial catheterization was not successful. Anesthetized horses were recovered from anesthesia, and rested for 5 hours before proceeding with the experimental protocol.

All catheters were flushed with heparinized isotonic saline before insertion and were connected to a pressure transducerg using a $2 \mathrm{~m}$ noncompliant connection line. ${ }^{\mathrm{h}}$ The pressure transducer was connected to a $1 \mathrm{~L} \mathrm{bag}$ containing lactated Ringer's solution ${ }^{\mathrm{i}}$ and maintained at a pressure of $300 \mathrm{~mm} \mathrm{Hg}$ using a pressure infusor bag. The pressure transducer was connected to a monitor ${ }^{k}$ with recent factory calibration. The pressure transducer was placed at the level of the point of the shoulder as an estimate for the location of the right atrium of the horse. The system was zeroed to atmospheric pressure approximately every hour. If the arterial trace was flattened and dampened, the system was flushed and the arterial trace subjectively assessed again. The distance from the transducer to the ground was measured and recorded in $\mathrm{cm}$. A $16 \mathrm{G} 6 \mathrm{~cm}$ catheter $^{1}$ was placed in the left jugular vein. Direct arterial BP was calculated and displayed by the BP monitor. ${ }^{\mathrm{k}}$

\section{Oscillometric NIBP}

The circumference of the tail base was measured to insure that the bladder of the BP cuff $^{\mathrm{m}}$ was approximately $40 \%$ of the width of the tail. ${ }^{20}$ Distance from the tail 
Table 1: Agreement analysis and descriptive statistics across all conditions and for normo hypertension and subnormal pressure

\begin{tabular}{|c|c|c|c|c|c|c|c|c|}
\hline & \multirow[b]{2}{*}{ Conditions } & \multicolumn{4}{|c|}{ Agreement } & \multicolumn{3}{|c|}{ Descriptive statistics } \\
\hline & & LCL* & UCL** & Acc ${ }^{* * *}$ & Prec $^{\dagger}$ & Mean & $\mathrm{SD}^{\$}$ & $P E^{\$ \$}(\%)$ \\
\hline \multirow[t]{4}{*}{ MAP } & All conditions & -23 & 15 & -4 & 10 & 130 & 14 & 15 \\
\hline & Subnormal BP & -19 & 18 & -1 & 9 & 94 & 6 & 19 \\
\hline & Normotension & -18 & 10 & -4 & 7 & 120 & 11 & 12 \\
\hline & Hypertension & -29 & 11 & -9 & 10 & 170 & 18 & 12 \\
\hline \multirow[t]{4}{*}{ SAP } & All conditions & -43 & 27 & -8 & 17 & 165 & 50 & 21 \\
\hline & Subnormal BP & -31 & 28 & -2 & 15 & 120 & 9 & 25 \\
\hline & Normotension & -28 & 17 & -6 & 11 & 150 & 14 & 15 \\
\hline & Hypertension & -62 & 23 & -20 & 21 & 230 & 12 & 18 \\
\hline \multirow[t]{4}{*}{ DAP } & All conditions & -34 & 21 & -7 & 14 & 100 & 27 & 28 \\
\hline & Subnormal BP & -27 & 18 & -5 & 11 & 78 & 77 & 28 \\
\hline & Normotension & -37 & 25 & -6 & 16 & 102 & 15 & 31 \\
\hline & Hypertension & -40 & 18 & -11 & 15 & 140 & 12 & 21 \\
\hline
\end{tabular}

All values are in $\mathrm{mm} \mathrm{Hg}$.

* Lower limits of agreement.

** Upper limits of agreement.

***Bias (accuracy) based on the Bland-Altman analysis.

†Precision; standard deviation (SD) of the bias (precision).

Mean invasive arterial BP (IBP) value.

$\$$ Maximum noninvasive BP (NIBP) value. Standard deviation (SD) of the IBP

$\$$ Percentage of error: $2 \times$ precision/mean.

MAP, mean arterial pressure; DAP, diastolic arterial pressure; SAP, systolic arterial pressure.

base to the floor was measured and recorded in centimeter. The NIBP cuff was snugly applied to the tail base with the bladder centered over the middle coccygeal artery. ${ }^{1,3}$ Systolic, diastolic, and mean arterial BPs were obtained using the oscillometric NIBP measured by the same monitor. ${ }^{k}$ The hydrostatic effect on the vertical distance between the cuff and right atrial level was corrected by adding $0.736 \mathrm{~mm} \mathrm{Hg}$ for each centimeter of height difference to the NIBP measurements. ${ }^{21}$

\section{Experimental design}

Heart rate and rhythm was monitored with an ECG, ${ }^{\mathrm{k}}$ and the heart was ausculted simultaneously after application to ensure correlation between heart rate and ECG. Oscillometric and invasive arterial BP were measured every 2 minutes for 14 consecutive measurements for each of 3 conditions reflecting normal BP, subnormal $\mathrm{BP}$, and hypertension. After application of the tail cuff, 5 acclimatizing recordings were collected before initiating data collection. If the machine did not record a measurement, the data point was discarded and the following data point was used until a total of 14 data points were achieved.

The BP of all horses was initially measured during normotension. Subsequently, hypertension was induced using a $1 \mathrm{mg} / \mathrm{mL}$ dobutamine solution ${ }^{\mathrm{n}}$ administered at a rate of $0.6 \mu \mathrm{g} / \mathrm{kg} / \mathrm{min}^{22}$ If the BP did not increase or if a persistent 2 nd degree AV block was observed on the ECG, a $0.02 \mathrm{mg} / \mathrm{kg}$ IV bolus of atropine ${ }^{\mathrm{e}}$ was given once. The dobutamine infusion was discontinued when the invasive SAP reached $275 \mathrm{~mm} \mathrm{Hg}$. The last
14 paired measurements before the infusion was discontinued were used for analysis. A rest period of 4 hours was allowed for wash out before induction of a lower $\mathrm{BP}$ with a single IV injection of acepromazine ${ }^{\mathrm{O}}$ at $0.1-0.2$ $\mathrm{mg} / \mathrm{kg} .{ }^{23}$ Measurements commenced when a decrease for IBP was observed to be below a MAP of $90 \mathrm{~mm} \mathrm{Hg}$. If the MAP did not drop below $90 \mathrm{~mm}$ in 30 minutes, the first value below $100 \mathrm{~mm} \mathrm{Hg}$ was used, and the measurements continued thereafter for 30 minutes.

\section{Statistical analysis}

Statistical analysis was performed using the open-source software $\mathrm{R}$ version $2.15 .0^{24}$ with the pastecs package ${ }^{25}$ for descriptive statistics and the MethComp package ${ }^{26}$ for computation of method agreement. Agreement analysis corrected for replicated measurements on each horse was performed, with accuracy defined as the mean difference (bias) between the methods. Precision was defined as the SD of the accuracy. Upper and lower limits of agreement were calculated as described by Bland and Altman ${ }^{27}$ modified with a random effect of horse by replicate as described by Carstensen et al. ${ }^{28}$ The percentage of error was calculated as $2 \times \mathrm{SD} /$ mean as described by Critchley and Critchley. ${ }^{29}$

\section{Results}

A total of 252 pairs of IBP and NIBP measurements were obtained from 7 horses. Five of these horses were treated with atropine during the dobutamine infusion. 


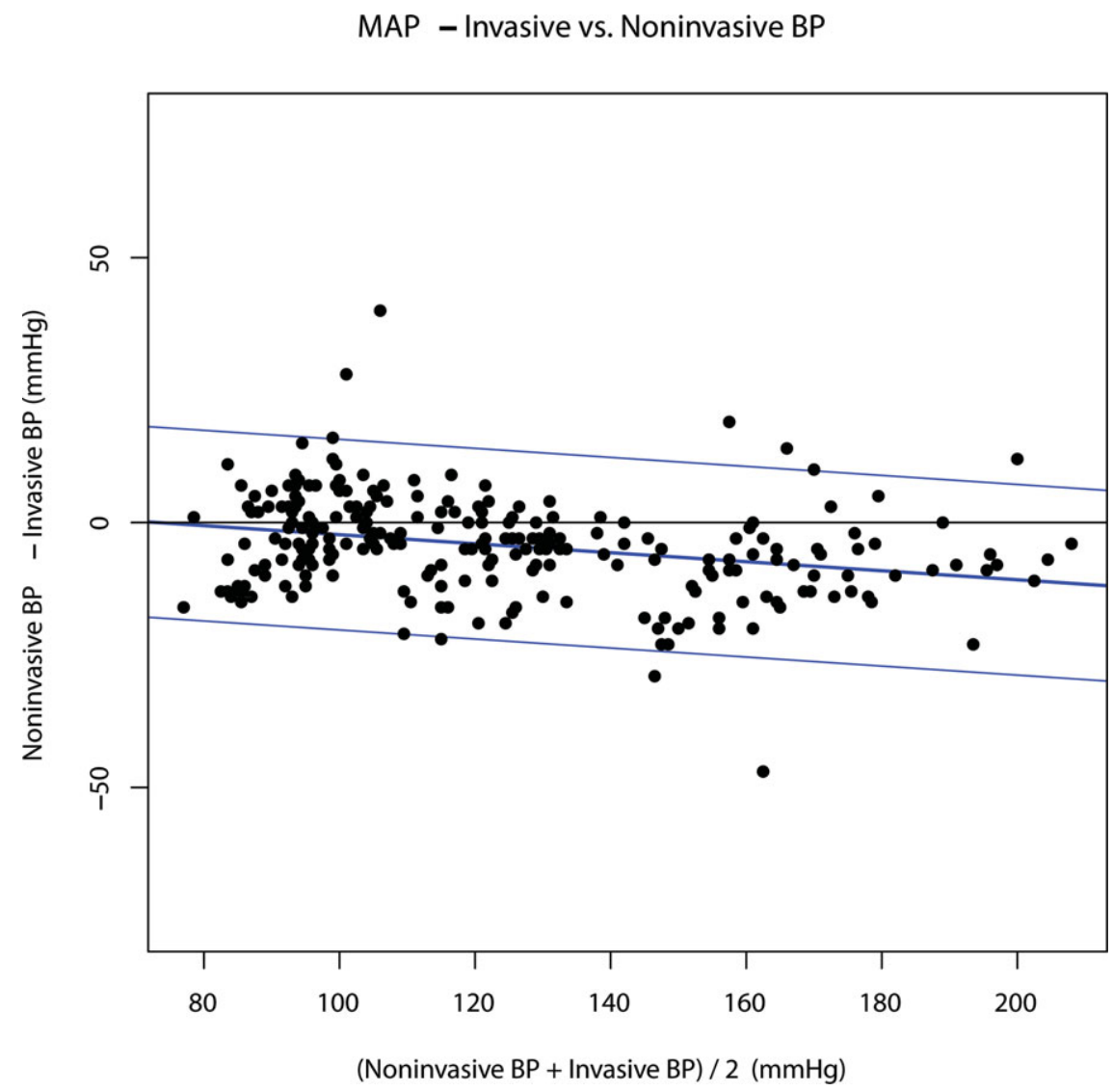

Figure 1: Bland-Altman agreement plot of mean arterial pressure (MAP) for invasive arterial BP (IBP) compared to noninvasive oscillometric blood pressure (NIBP) across normal BP, subnormal BP, and hypertension. The lines are regressed to fit the skewed distribution.

The heart rate for the horses during normotension were (mean $\pm \mathrm{SD}$ ) $34 \pm 5$ beats per minute (bpm), $54 \pm 16 \mathrm{bpm}$ during dobutamin infusion and $35 \pm 6$ bpm for injection with acepromazine.

Agreement and descriptive statistics for SAP, MAP, and DAP are listed in Table 1. The IBP MAP measurements ranged from 78 to $210 \mathrm{~mm} \mathrm{Hg}$, $(130 \pm 14 \mathrm{~mm} \mathrm{Hg})$. The MAP after acepromazine injection ranged from 78 to $110 \mathrm{~mm} \mathrm{Hg}(94 \pm 6 \mathrm{~mm} \mathrm{Hg})$, the MAP for normotension ranged from 94 to $140 \mathrm{~mm} \mathrm{Hg}$, $(120 \pm 11 \mathrm{~mm} \mathrm{Hg})$, and the hypertensive MAP ranged from 130 to $210 \mathrm{~mm} \mathrm{Hg}$ $(170 \pm 18 \mathrm{~mm} \mathrm{Hg})$. Across all BP conditions, the IBP SAP ranged from 100 to $312 \mathrm{~mm} \mathrm{Hg}$ and the IBP DAP ranged from 55 to $178 \mathrm{~mm} \mathrm{Hg}$. The oscillometric NIBP device did not reliably display NIBP measurements for horses during periods of 2nd degree AV block and resumed to NIBP measurements once the AV block resolved following administration of atropine. The measured tail circumferences ranged from 19 to $24 \mathrm{~cm}$ with a mean of $21 \pm 2 \mathrm{~cm}$. This resulted in a cuff width-to-tail circumference ratio ranging from 0.60 to 0.48 . When using the mean tail circumference of $21 \mathrm{~cm}$, the cuff width-to-tail circumference was 0.55 .
The accuracy and precision across all $\mathrm{BP}$ values and for each of the specific BP targets are described in Table 1. The accuracy for the NIBP MAP across all BP values, using the IBP as a reference standard, was $-4 \mathrm{~mm} \mathrm{Hg}$, with a precision of $10 \mathrm{~mm} \mathrm{Hg}$ and percentage error of $15 \%$. The accuracy for NIBP SAP across all BP measurements was $-8 \mathrm{~mm} \mathrm{Hg}$, with a precision of $17 \mathrm{~mm} \mathrm{Hg}$ and percentage error of $21 \%$. For NIBP DAP, the accuracy across all conditions was $-8 \mathrm{~mm} \mathrm{Hg}$, with a precision of $14 \mathrm{~mm}$ $\mathrm{Hg}$ and a percentage error of $28 \%$.

A regression line fitted to the bias of MAP (Figure 1), SAP (Figure 2), and DAP (Figure 3) as a function of the average of IBP and NIPB show an increased negative bias as the BP increased, with a more negative slope for SAP compared to MAP. In addition, SAP and DAP have wider limits of agreement compared to MAP (Figures 1$3)$. The mean $( \pm S D)$ heart rate during normotension was $34 \pm 5 /$ min during induction of subnormal BP, it was $35 \pm 6 / \mathrm{min}$ and for hypertension it was $55 \pm 17 / \mathrm{min}$. Horses receiving a dose of $0.2 \mathrm{mg} / \mathrm{kg}$ acepromazine became restless and started to pace in their stalls, while the infusion of dobutamine did not influence the behavior of any horses. 
SAP - Invasive vs. Noninvasive BP

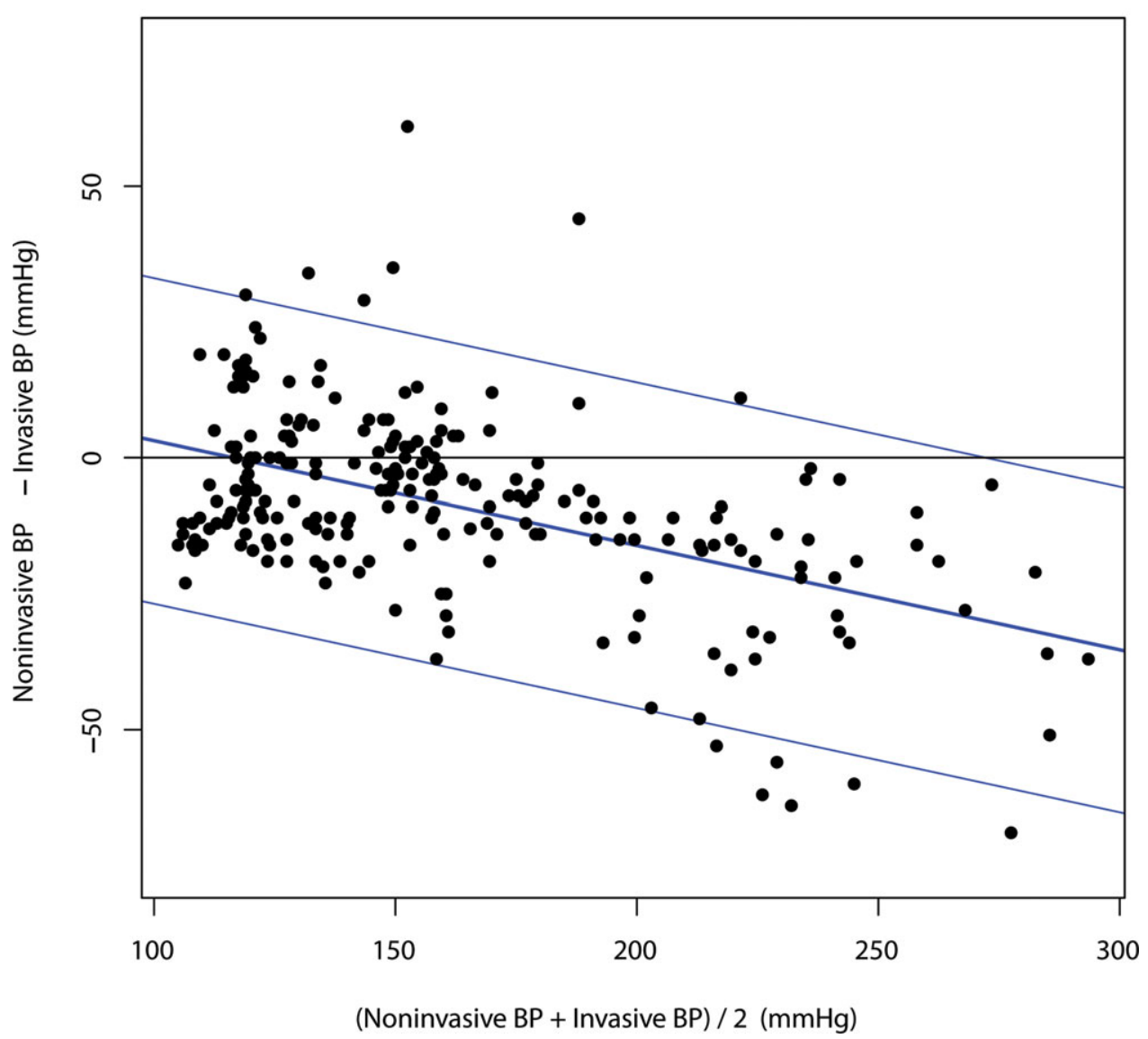

Figure 2: Bland-Altman agreement plot of systolic arterial pressure (SAP) for Invasive arterial BP (IBP) compared to noninvasive oscillometric blood pressure (NIBP) across normal BP, subnormal BP, and hypertension. The lines are regressed to fit the skewed distribution. One outlier is outside the plot area.

\section{Discussion}

The accuracy of oscillometric NIBP measurement of MAP in this study (using DABP as the reference standard) was $-4 \mathrm{~mm} \mathrm{Hg}$, while the overall precision was $10 \mathrm{~mm} \mathrm{Hg}$. Oscillometric MAP had the lowest measurement error $(12 \%-15 \%)$ during normotension and hypertension, with a larger error during measurement of subnormal BP. The oscillometric SAP had a larger error during subnormal pressure conditions whereas DAP measurement was accurate but imprecise across all BP ranges. These data suggest that oscillometric NIBP is an acceptable method for monitoring MAP in the standing, conscious horse.

Nout et $\mathrm{al}^{13}$ conducted a method agreement study of IBP versus oscillometric NIBP in 10 anesthetized and 4 conscious foals, and reported that the bias for MAP was $-0.5 \mathrm{~mm} \mathrm{Hg}$, compared to $-4 \mathrm{~mm} \mathrm{Hg}$ in the present study. The report also demonstrated a lower limit of agreement for MAP of $-17 \mathrm{~mm} \mathrm{Hg}$ and the upper limit of agreement to be $16 \mathrm{~mm} \mathrm{Hg}$, compared to slightly wider limits of agreement in the current study, of $-23 \mathrm{~mm} \mathrm{Hg}$ to $15 \mathrm{~mm} \mathrm{Hg}$. Nout et $\mathrm{al}^{13}$ had lower accuracy and precision for NIBP measurement of SAP and DAP, but the limits of agreement were slightly narrower for systolic pressure ( -18 to $48 \mathrm{~mm} \mathrm{Hg}$ ) compared to the present report ( -43 to $27 \mathrm{~mm} \mathrm{Hg}$ ). The limits of agreement for DAP were also narrower $(-18$ to $17 \mathrm{~mm} \mathrm{Hg}$ ) compared to this study ( -34 to $21 \mathrm{~mm} \mathrm{Hg}$ ).

Lower heart rates, particularly if accompanied by arrhythmias such as sinus bradycardia or AV block can result in inaccuracies in oscillometric NIBP measurement. ${ }^{30}$ Adult horses have a lower heart rate than foals and, as demonstrated in this study, can frequently suffer from AV block, which could explain why Nout et $\mathrm{al}^{13}$ had a lower bias for MAP compared to this report. In addition, including linked replicates on each horse widens the limits of agreement. ${ }^{27}$ There was a markedly higher percentage of error for oscillometric MAP and SAP measurement during 


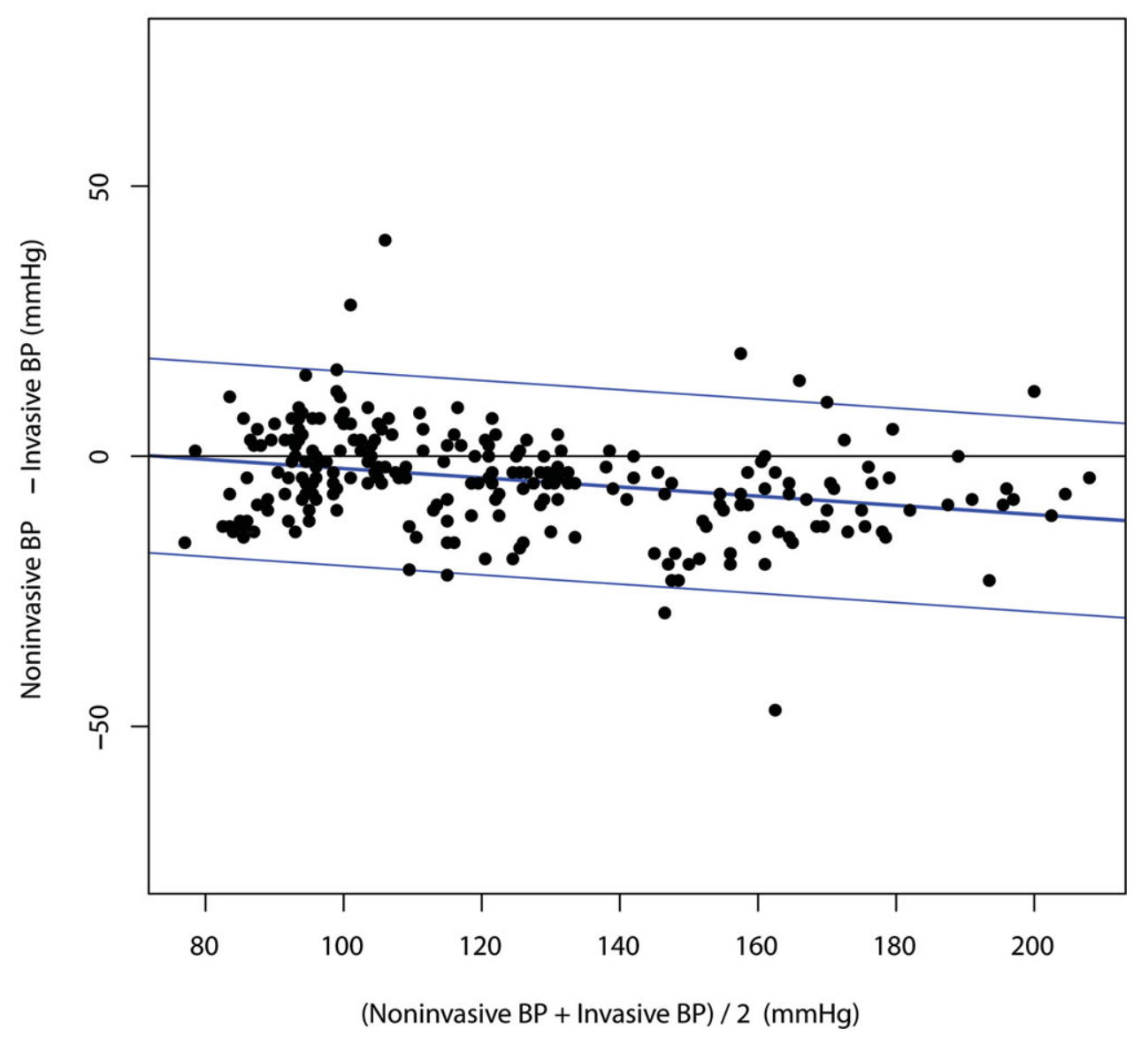

Figure 3: Bland-Altman agreement plot of diastolic arterial pressure (DAP) for invasive arterial BP (IBP) compared to noninvasive oscillometric blood pressure (NIBP) across normal BP, subnormal BP, and hypertension. The lines are regressed to fit the skewed distribution. One outlier is outside the plot area.

subnormal BP, which raises concern for the accuracy of NIBP measures in clinical patients with low BP, and this phenomenon may be even more pronounced with MAP $<60 \mathrm{~mm} \mathrm{Hg}$. The explanation for this is probably related to the technical function of the tested oscillometric device.

The induction of hypotension by administration of acepromazine proved to be difficult in this study. Monitoring was carried out for an hour to ensure the full efficacy of the drug, ${ }^{23,31}$ but the lowest recorded MAP was $78 \mathrm{~mm} \mathrm{Hg}$, which does not meet traditional definitions for hypotension (usually $60 \mathrm{~mm} \mathrm{Hg}$ or less). ${ }^{5}$ This could be explained by the fact that the horses were euvolemic and possessed an intact sympathetic nervous system that allowed the body to compensate for mild to moderate reductions in SVR or because there was a prolonged effect of the dobutamine. Despite hypotension not being achieved in this study, the ranges of MAP studied in the subnormal, normo- and hyperten- sive groups are different, and a minor change in pressure range was achieved. Leise et $\mathrm{al}^{32}$ achieved comparable pressures using an acepromazine dose of $0.04 \mathrm{mg} / \mathrm{kg}$ IM, while Parry et al ${ }^{31}$ reported MAP as low as $67 \mathrm{~mm}$ $\mathrm{Hg}$ in horses using acepromazine at a dose of $0.1 \mathrm{mg} / \mathrm{kg}$ IV.

European recommendations for human NIBP devices define an accuracy $\leq 5 \mathrm{~mm} \mathrm{Hg}$ as very accurate, 6-10 $\mathrm{mm} \mathrm{Hg}$ as slightly inaccurate, $11-15 \mathrm{~mm} \mathrm{Hg}$ as moderately inaccurate, and variability of $>15 \mathrm{~mm} \mathrm{Hg}$ is very inaccurate. ${ }^{33}$ Using this definition, the oscillometric NIBP MAP from the device studied in this report can be considered very accurate during subnormal BP and normotension, but slightly inaccurate in horses with hypertension.

The specific algorithms and cuff designs that are used in different oscillometric NIBP machines may contribute to variability, when compared to IBP measurements. A recent comparison of three NIBP devices in 
hypertensive dogs demonstrated wide limits of agreement that led to categorization of individual dogs into different $\mathrm{BP}$ groups depending on the apparatus used. ${ }^{34}$ When comparing IBP to NIBP, it is also important to remember that the device's outcome measurements are not directly comparable because IBP directly measures SAP and DAP and calculates MAP whereas oscillometric NIBP devices measure MAP and calculate SAP and DAP. ${ }^{9}$ Oscillometric NIBP also calculates an average MAP over several heart beats, whereas IBP measurements reflect the beat-to-beat variation and momentary changes in head height, ${ }^{35}$ thereby increasing the variability between the methods.

There are a number of other limitations of the current study. Compared with a previous study in horses, ${ }^{16}$ the cuff size used in the present experimental design resulted in a larger cuff width-to-tail circumference ratio (mean of $0.57 \pm 0.05$ ). Latshaw et $\mathrm{al}^{16}$ reported that the optimal ratio was approximately 0.2 , while other veterinary studies have reported 0.5 and 0.3 in $\operatorname{dogs}^{36,37}$ and 0.3 in cats. ${ }^{38}$

Another important limitation of the current study is that all horses used were clinically healthy. Cardiovascular regulatory factors may vary in the critically ill or painful horse, which may alter the performance of oscillometric monitors in these cases. Future studies comparing the same oscillometric device to IBP in clinically ill horses are warranted to verify appropriate NIBP function in these situations. These studies are important because hypotension in the clinical setting is often caused by hypovolemia, and not by vasodilation as in the present study. A better model of hypotension could be achieved with experimental hypovolemia; however, based on the results in our study, we suspect that the oscillometric NIBP monitor would have low accuracy in this model. Assessment of hypotension in critically ill cases using the tested NIBP monitor should be performed cautiously, as the monitor became less accurate and precise with subnormal BP.

\section{Acknowledgments}

We acknowledge the help, enthusiasm, and contribution from the late Gert Skibsted Jacobsen for planning of the accuracy evaluation, GE Healthcare Denmark for lending us the Datex Ohmeda B30 monitor with equipment, and especially Hanne Ibsen. In addition, we are grateful to the veterinary technicians Stine Post, Anette Larsen, and Bent Hansen for invaluable help during data collection and anesthesia. Rikke Buhl and Christina Kronborg are acknowledged for pilot work with the Datex Ohmeda S5 at the University of Copenhagen large animal hospital.

\section{Footnotes}

a Emla cream 5\%, AstraZeneca, Copenhagen S, Denmark.

b FloSwitch, 20 G, $1.10 \times 45 \mathrm{~mm}$, Becton, Dickinson and Company, Albertslund, Denmark.

c Animal Polster, Snogg Industri AS, Mosby, Norway.

d Narcoxyl vet, $20 \mathrm{mg} / \mathrm{mL}$, MSD Animal Health, Ballerup, Denmark.

e Atropin sulfate, $10 \mathrm{mg} / \mathrm{mL}$, Pharmacy at faculty of LIFE Sciences, Frederiksberg, Denmark.

f Ketaminol, $100 \mathrm{mg} / \mathrm{mL}$, MSD Animal Health.

g TruWave Disposable Pressure Transducer, Edwards Lifesciences A/S, Holte, Denmark.

h Connecta PE Line M/F $200 \mathrm{~cm}$. BD a/s.

i Lactated Ringer's, Fresenius Kabi.

j Pressure Infusion, Infu-Surg 1L, Ethox medical, Buffalo, NY.

k Datex-Ohmeda B30, GE Healthcare, General Electric Company, Denmark \& Datex-Ohmeda division, Finland.

1 Intraflon 2, 16 g, Vygon, Paris, France.

m CRITIKON, DURA-CUF® $17-25 \mathrm{~cm}$, GE Healthcare Europe GmbH, Brondby, Denmark.

n Dobutrex, $12.5 \mathrm{mg} / \mathrm{mL}$, PharmaCoDane, Herlev, Denmark. $1 \times 20 \mathrm{~mL}$ diluted with $230 \mathrm{~mL}$ lactated Ringer's solution.

- Plegicil, $10 \mathrm{mg} / \mathrm{mL}$, ScanimalHealth, Farum, Denmark.

\section{References}

1. Magdesian KG. Monitoring the critically ill equine patient. Vet Clin North Am Equine Pract 2004; 20(1):11-39.

2. Peiro JR, Barnabe PA, Cadioli FA, et al. Effects of lidocaine infusion during experimental endotoxemia in horses. J Vet Intern Med 2010; 24(4):940-948.

3. Taylor PM. Techniques and clinical application of arterial blood pressure measurement in the horse. Equine Vet J 1981; 13(4):271275.

4. Wagner AE. Complications in equine anesthesia. Vet Clin North Am Equine Pract 2008; 24(3):735-752, x.

5. Bussieres G, Jacques C, Lainay O, et al. Development of a composite orthopaedic pain scale in horses. Res Vet Sci 2008; 85(2):294306.

6. Bailey SR, Habershon-Butcher JL, Ransom KJ, et al. Hypertension and insulin resistance in a mixed-breed population of ponies predisposed to laminitis. Am J Vet Res 2008; 69(1):122-129.

7. Frank N, Geor RJ, Bailey SR, et al. Equine metabolic syndrome. J Vet Intern Med 2010; 24(3):467-475.

8. Kiers HD, Hofstra JM, Wetzels JF. Oscillometric blood pressure measurements: differences between measured and calculated mean arterial pressure. Neth J Med 2008; 66(11):474-479.

9. Mayet J, Hughes A. Cardiac and vascular pathophysiology in hypertension. Heart 2003; 89(9):1104-1109.

10. Gay CC, Carter J, McCarthy M, et al. The value of arterial blood pressure measurement in assessing the prognosis in equine colic. Equine Vet J 1977; 9(4):202-204.

11. Bur A, Herkner H, Vlcek M, et al. Factors influencing the accuracy of oscillometric blood pressure measurement in critically ill patients. Crit Care Med 2003; 31(3):793-799.

12. Giguere S, Knowles HA, Jr., Valverde A, et al. Accuracy of indirect measurement of blood pressure in neonatal foals. J Vet Intern Med 2005; 19(4):571-576.

13. Nout YS, Corley KTT, Donaldson LL, Furr MO. Indirect oscillometric and direct blood pressure measurements in anesthetized and conscious neonatal foals. J Vet Emerg Crit Care 2002; 12(2):7580.

14. Branson KR. A clinical evaluation of an oscillometric blood pressure monitor on anesthetized horses. J Equine Vet Sci 1997; 17(10):537540.

15. Hahn AW, Garner HE, Coffman JR, Sanders CW. Indirect measurement of arterial blood pressure in the laboratory pony. Lab Anim Sci 1973; 23(6):889-893.

16. Latshaw H, Fessler JF, Whistler SJ, Geddes LA. Indirect measurement of mean blood pressure in the normotensive and hypotensive horse. Equine Vet J 1979; 11(3):191-194. 
17. Shapiro DS, Loiacono LA. Mean arterial pressure: therapeutic goals and pharmacologic support. Crit Care Clin 2010; 26(2):285-293.

18. Brown S, Atkins C, Bagley R, et al. Guidelines for the identification, evaluation, and management of systemic hypertension in dogs and cats. J Vet Intern Med 2007; 21(3):542-558.

19. Matthews NS, Hartsfield SM, Cornick JL, et al. A comparison of injectable anesthetic combinations in horses. Vet Surg 1991; 20(4):268273.

20. Pickering TG, Hall JE, Appel LJ, et al. Recommendations for blood pressure measurement in humans and experimental animals: Part 1: blood pressure measurement in humans: a statement for professionals from the Subcommittee of Professional and Public Education of the American Heart Association Council on High Blood Pressure Research. Hypertension 2005; 45(1):142-161.

21. Gay CC, McCarthy M, Reynolds WT, Carter J. A method for indirect measurement of arterial blood pressure in the horse. Aust Vet J 1977; 53(4):163-166.

22. Schauvliege S, Gasthuys F. Drugs for cardiovascular support in anesthetized horses. Vet Clin North Am Equine Pract 2013; 29(1):1949 .

23. Ballard S, Shults T, Kownacki AA, et al. The pharmacokinetics, pharmacological responses and behavioral effects of acepromazine in the horse. J Vet Pharmacol Ther 1982; 5(1):21-31.

24. R Core Team. R: A Language and Environment for Statistical Computing, 3.0.0 edn. Vienna, Austria: R Foundation for Statistical Computing; 2013. Available at: http:/ /www.R-project.org.

25. Ibanez F, Grosjean P, Eritenne M. pastecs: Package for Analysis of Space-Time Ecological Series, 1.3-11 edn; Vienna, Austria: 2009 Available at: http://CRAN.R-project.org/package=pastecs:Rproject.

26. Carstensen B, Gurrin L, Ekstrom C. MethComp: Functions for analysis of method comparison studies. $\mathrm{R}$ package version 1.15 edn; Gentofte, Denmark: 2012. Available at: http://CRAN.Rproject.org/package=MethComp: R-project.

27. Bland JM, Altman DG. Agreement between methods of measurement with multiple observations per individual. J Biopharm Stat 2007; 17(4):571-582.
28. Carstensen B, Simpson J, Gurrin LC. Statistical models for assessing agreement in method comparison studies with replicate measurements. Int J Biostat 2008; 4(1):Article 16.

29. Critchley LA, Critchley JA. A meta-analysis of studies using bias and precision statistics to compare cardiac output measurement techniques. J Clin Monit Comput 1999; 15(2):85-91.

30. Hamlin RL, Kittleson MD, Rice D, et al. Noninvasive measuremen of systemic arterial pressure in dogs by automatic sphygmomanometry. Am J Vet Res 1982; 43(7):1271-1273.

31. Parry BW, Anderson GA, Gay CC. Hypotension in the horse induced by acepromazine maleate. Aust Vet J 1982; 59(5):148152.

32. Leise BS, Fugler LA, Stokes AM, et al. Effects of intramuscular administration of acepromazine on palmar digital blood flow, palmar digital arterial pressure, transverse facial arterial pressure, and packed cell volume in clinically healthy, conscious horses. Vet Surg 2007; 36(8):717-723.

33. O'Brien E, Pickering T, Asmar R, et al. Working Group on Blood Pressure Monitoring of the European Society of Hypertension International Protocol for validation of blood pressure measuring devices in adults. Blood Press Monit 2002; 7(1):3-17.

34. Wernick MB, Hopfner RM, Francey T, Howard J. Comparison of arterial blood pressure measurements and hypertension scores obtained by use of three indirect measurement devices in hospitalized dogs. J Am Vet Med Assoc 2012; 240(8):962-968.

35. Parry BW, Gay CC, McCarthy MA. Influence of head height on arterial blood pressure in standing horses. Am J Vet Res 1980; 41(10):1626-1631.

36. Shih A, Robertson S, Vigani A, et al. Evaluation of an indirect oscillometric blood pressure monitor in normotensive and hypotensive anesthetized dogs. J Vet Emerg Crit Care 2010; 20(3):313-318.

37. Sawyer DC, Brown M, Striler EL, et al. Comparison of direct and indirect blood pressure measurement in anesthetized dogs. Lab Anim Sci 1991; 41(2):134-138.

38. Grandy JL, Dunlop CI, Hodgson DS, et al. Evaluation of the Doppler ultrasonic method of measuring systolic arterial blood pressure in cats. Am J Vet Res 1992; 53(7):1166-1169. 